Richards, B.S. ; Schäfer, A.I. (2003) Photovoltaic-powered Desalination System for remote Australian Communities, Renewable Energy 28, $2013-2022$. doi:10.1016/S0960-1481(03)00081-8

\section{Photovoltaic-powered Desalination System for Remote Australian Communities}

Bryce S. Richards ${ }^{1, *}$ and Andrea I. Schäfer ${ }^{2}$

${ }^{1}$ Centre for Photovoltaic Engineering, The University of New South Wales, Sydney, New South Wales 2052, AUSTRALIA,

${ }^{2}$ Environmental Engineering, University of Wollongong, Wollongong, New South Wales 2522, AUSTRALIA

\section{Abstract}

This paper reports on the design and successful field testing of a photovoltaic (PV)-powered desalination system. The system described here is intended for use in remote areas of the Australian outback, where fresh water is extremely limited and it is often necessary to drink high-salinity bore water. A hybrid membrane configuration is implemented, whereby an ultrafiltration (UF) module is used for removing particulates, bacteria and viruses, while a reverse osmosis (RO) or nanofiltration (NF) membrane retains the salts. The concepts of water and energy recovery are implemented in the design. Field trials, performed in White Cliffs (New South Wales), demonstrated that clean drinking water was able to be produced from a variety of feed waters, including high salinity $(3500 \mathrm{mg} / \mathrm{L})$ bore water and high turbidity (200 NTU) dam water. The specific energy consumption ranged from $2-8$ $\mathrm{kWh}$ per $1 \mathrm{~m}^{3}$ of disinfected and desalinated drinking water, depending on the salinity of the feed water determined to be in the range $6-7$ bar.

\section{Introduction}

There is a limited supply of fresh drinking water in many remote regions in Australia, and it has been estimated that about 800 indigenous communities in Australia rely on groundwater as their main source of drinking water [1]. About 350 of these communities experienced water shortages in 1998, half of which were attributed to mechanical breakdown, effecting nearly 18000 people [1]. Brackish groundwater bores, having a salt concentration of $1500-5000 \mathrm{mg} / \mathrm{L}$, can be found in significant volumes throughout the majority of Australia [2]. The consumption of brackish water has been linked . The Adlitionally, the to poor helth inction, the extension of a national electricity grid possible. Therefor, these conmmunties are often dinking water of substandard quality, as they do not possess the electrical power or appropriate technology to purify the water. However, the solar radiation resource in Australia is excellent [4], as shown in Figure 1, making photovoltaics (PV) the obvious choice as a renewable energy source. Therefore, a small, robust, desalination system powered by PV panels was developed in order to enable remote communities, both in Australia and around the world, to obtain high-quality drinking water from brackish water sources.

\section{$2 \quad$ Background and Approach}

An overview over membrane processes available for water treatment is given in Figure 2. For remote communities two main issues are of concerns; i) removal of microorganisms and pathogens which cause diseases such as infections and diarrhoea, and ii) desalination. More location specific issues like removal of pesticides or natural organics, which form disinfection by-products upon chlorination, may removal of pesticides or natural organics, which form disinfection by-products upon chlorination, may
also exist. Figure 2 shows that microfiltration (MF) can remove bacteria, but for the removal of viruses also exist. Figure 2 shows that microfiltration (MF) can remove bacteria, but for the removal of viruses
ultrailtration (UF) is required. Nanofiltration (NF) removes multivalent salts such as calcium, iron, manganese, uranium, etc ans some pesticides whereas reverse osmosis (RO) is required to remove all types of salts and most trace pollutants.

There have been several renewable energy-powered desalination systems designed to produce 100 $3000 \mathrm{~L}$ of clean drinking water per day using reverse osmosis membranes $[2,5,6,7,8,9,10]$. The systems desioned by Keefer et al. [5] and Herold et al. [7, 8] used reverse osmosis (RO) membranes operating at high-pressures (up to $60 \mathrm{bar}$ ) in order to desalinate sea water (typical salinity $35000 \mathrm{mg} / \mathrm{L}$ ), while the remainder are designed for brackish water $[2,6,9,10]$. The specific energy consumption the amount of energy $(\mathrm{kWh})$ required to produce $1 \mathrm{~m}^{3}$ of clean drinking water - of these systems varied greatly, from $1.2-19 \mathrm{kWh} / \mathrm{m}^{3}$. The amount of power, or more specifically current, required to drive the pumps is directly proportional to the operating pressure. As well as the RO membrane to remove the salt, a pre-treatment stage is usually required to remove larger particulates and prevent damage to the RO membrane. The pre-treatment stage often consists of either 5 or 20 micron filters, or sand filters. Regular replacement of fiters that have been blocked due to biological fouling (e.g., bacteria or algae growth on the filter) has been reported in the literature [2]

Many existing water treatment technologies in remote indigenous communities are unsustainable for several reasons. The designer of a successful appropriate technology needs to consider the following issues:

i) the cultural realities and the impact of remoteness, rather than planning for urban standards;

ii) how highly the community values the resource;

iii) identifying the actual, rather than perceived, needs of the community;

iv) the technology must be simple and robust to be able to sustain life in a remote community and a harsh environment;

v) the technology must be wanted by the community, and should provide water treated to the level required by the community; and

vi) training in maintenance and education for local community members. 
Richards, B.S. ; Schäfer, A.I. (2003) Photovoltaic-powered Desalination System for remote Australian Communities, Renewable Energy 28, 2013-2022.

The schematic diagram in Figure 3 shows the system configuration used in this work. The approach has been to use a hybrid membrane system. In this configuration, an UF membrane is submerged in the feed tank as a prefilter, while a RO or NF membrane removes the salt from the water. The choice of NF or RO membranes depends on the raw water quality and is expected to influence power consumption due to different pressure requirements. There are several advantages to the hybrid UF$\mathrm{NF} / \mathrm{RO}$ configuration, including:

i) the UF membrane is suspended in the feed tank, allowing heavier particulates to sink to the bottom of the tank rather than accumulating them on the membrane surface;

ii) the UF membrane can remove all viruses and bacteria, and may alone be sufficient for the treatment of low-salinity surface waters where disinfection is the main concern;

iii) where desalination and hence the $\mathrm{NF} / \mathrm{RO}$ process are required, the system offers a dual barrier to microorganisms;

iv) the pressure drop across the UF membrane is small ( $\sim 0.5 \mathrm{bar})$, and therefore the same highpressure pump (HPP) that delivers water to the NF/RO module can be used to draw wate through the UF module;

v) the cleaning requirements of the $\mathrm{NF} / \mathrm{RO}$ membranes will be reduced due to the high-quality feed produced by the UF membrane;

vi) variability in membrane choice depending on water quality; NF membranes are designed to operate at lower pressures $(5-10 \mathrm{bar})$ than RO membranes - the salt rejection is sufficient to achieve clean drinking water (salinity $<500 \mathrm{mg} / \mathrm{L}$ ) from brackish water sources, but the powe requirements are significantly reduced; and

vii) both the concepts of energy and water conservation are employed in this design, with a high-flow, low-pressure pump being incorporated into the recycle stream.

The concepts of, firstly, water conservation and, secondly, energy conservation are defined as follows. Low a recovery ratios - the ratio of clean water (permeate) produced to feed flow (typically $10-25 \%$ ) - are commonly to reduce fouling of the NF/RO membrane. However, the low recovery means that 4 - 10 times more feed water must be pumped through the system. Water conservation becomes an issue when the natural recharge rate of the bore is slow, and the system will be running the bore temporarily dry. For this reason, a significant fraction of the reject flow is recycled back though the $\mathrm{NF} / \mathrm{RO}$ membrane. This is not necessary if latge amounts of water are used for non-potable purposes

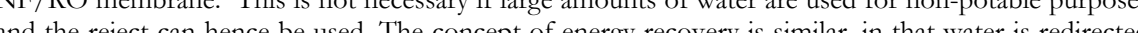
back through the membrane instead of being discher only $\sim 0.5$ bar less than at the NF/RO inlet, and therefore a significant amount of work has been done raising the pressure of this water to $5-10$ bar. Thus, by using a positive displacement pump, the differential pressure of $\sim 0.5$ bar can be added to the recycle stream so that it may flow once more through the membrane.

The current system uses two Dankoff Solar Slowpumps, model 1322 for the high-pressure pump (HPP) and 2507 for the recycle pump (RP). The RP and HPP operate directly off the one and three PV panels (BP Solar 585F, monocrystalline silicon, laser-grooved technology) via a maximum power point tracker (MPPT). For an operating pressure of $8 \mathrm{bar}$, the HPP draws $100 \mathrm{~W}$ and produces a flow of $100 \mathrm{~L} / \mathrm{h}$, while the RP only requires an additional $50 \mathrm{~W}$ to recycle $720-900 \mathrm{~L} / \mathrm{h}$ back into the $\mathrm{NF} / \mathrm{RO}$ membrane. This enables the system to produce about $500 \mathrm{~L}$ of clean water per day with $5 \mathrm{kWh} / \mathrm{m}^{2}$ of daily solar insolation. Significantly, the system is being optimised to run without the presence of batteries, due to:

i) the additional electrical losses and reduced system efficiency;

ii) increased maintenance;

iii) use of strong chemicals and the risk of spillage; and

iv) the problems associated with battery recycling in developing countries.

\section{Results and Discussion}

Field testing was performed using the prototype system (an image of which is shown in Figure 4) a White Cliffs (north-western New South Wales, Australia) in April 2002. White Cliffs was chosen as the field test site due to its remote location, its small population (approx. 250), the frequent water shortages during winter due to the influx of tourists, and its excellent solar resource. Three different types of water were used for experiments - i) rainwater with $2000 \mathrm{mg} / \mathrm{L} \mathrm{NaCl}$ added, ii) White Cliffs dam water $(150 \mathrm{mg} / \mathrm{L}$ salinity but very turbid), and iii) bore water from Glenhope Station ( $3500 \mathrm{mg} / \mathrm{L}$ salinity and a pungent sulphurous odour).

The data in the left hand side of Figure 5 shows that about $90 \mathrm{~W}$ is required to produce a clean water flow of about $40 \mathrm{~L} / \mathrm{h}$ at an operating pressure of 9 bar when $2000 \mathrm{mg} / \mathrm{L} \mathrm{NaCl}$ in rainwater is used as the feed water. Increasing the operating pressure from 9 to 10 bar increased the power consumption dramatically, however the permeate flow remained essentially unchanged. This is due to the operating characteristics of the rotary vane HPP pump, where the flow actually exhibits very little dependence on the operating pressure. Therefore, since the permeate flow does not increase with pressure, the specific eneroy consumption increases. The operating characteristics of the HPP pump lend itself to the design of systems where a definite volume of water is required daily. In a RO desalination system, this will also result in the same amount of water being produced when membrane fouling occurs, albeit at an also result in the same amount of water being produced when membrane fouling occurs, albeit at an
increased specific energy consumption. The solid construction of the pumps (brass, stainless steel and graphite) results in minimal maintenance (one every five years) and a long expected service life (twenty years).

In Figure 6, the permeate flow, power consumption, salt retention and specific energy consumption are compared for dam and bore water at an operating pressure of 5 bar. The salt retention of the NF membrane is excellent, between 93 and $95 \%$, resulting in a permeate salinity that lies well within the World Health Organisation recommended limit of $500 \mathrm{mg} / \mathrm{L}[10]$. Although the power consumption is higher for dam water, this is primarily because of the significantly higher permeate flux $(32 \mathrm{vs} 9 \mathrm{~L} / \mathrm{h}$ ) This results in a significantly higher specific energy consumption for the high salinity bore water, which can be understood as the pump is having to work harder to force the water through the membrane due to the osmotic pressure imposed by the salt in the feedwater.

A range of system operating pressures was investigated for the bore water. Figure 7 shows that a minimum in the specific energy consumption could be expected somewhere in between 6 and 7 bar, where clean water is being produced for about $8 \mathrm{kWh} / \mathrm{m}^{3}$. This value is slightly less than results from another system, which also used groundwater with about $3500 \mathrm{mg} / \mathrm{L}$ salinity [10]. The specific energy consumption can be reduced significantly with an energy recovery turbine or centrifugal pump operated in reverse. Figure 8 illustrates that the operating pressure of the system is directly proportional to the current drawn from the panels. The system voltage (not plotted) remains very constant at $15.0 \pm 0.1 \mathrm{~V}$ due to the action of the MPPT. The salt rejection remained high for all operating pressures greater than 4 bar.

Although the system performed very satisfactorily during field testing, further optimisation is still required. During field testing the system was operated in single pass mode only, and the recycle pump was not used. In addition, the experiments performed during field testing were designed for determining the performance of the membranes. This meant that in order to avoid variations in the membrane performance due to solar availability, the high pressure pump was powered by three $85 \mathrm{~W}_{\mathrm{p}}$ meralla the solar inalance did not reduce considerably at all. Therefor, further system testing is required, whereby the pressure is set to constant level and the water production is monitored throughout the whole day as a function of sola irradiance. Further reduction of the amount of power required for certain feed-waters will also be performed. For example, the dam water used here is already low salinity, and therefore energy is being wasted by pumping this water through the NF/RO membrane, whereas the UF membrane has already removed all the turbidity, viruses and bacteria from the water. 
Richards, B.S. ; Schäfer, A.I. (2003) Photovoltaic-powered Desalination System for remote Australian Communities, Renewable Energy 28, $2013-2022$.

A PV-powered desalination system has been successfully designed, and field testing has been performed in the Australian outback. The system is based on a hybrid membrane configuration, with an ultrafiltration (UF) module for removing particulates, bacteria and viruses and a nanofiltration (NF) or reverse osmosis (RO) membrane for removing salts. The design maximises the use of sparse water resources by using water recovery. The concept of energy recovery was also investigated. The system produced clean drinking water from a variety of feed waters, including high salinity $(3500 \mathrm{mg} / \mathrm{L}$ ) water. The a c e f corent dawn from the PV pands depended lirectly on he ope ( pump, as is exped. The a for pumper a is expected. ranged from 2 to $8 \mathrm{kWh} / \mathrm{m}$, depending on the salinity of the feed water and the system operating conditions. The optimum operating pressure when filtering bore water was determined to be in the range $6-7$ bar.

\section{Acknowledgements}

The initial stages of this project were funded through the Faculty of Engineering RIBG Grant Scheme (University of New South Wales). Zenon Environmental (Canada) and Dow Chemicals (Australia) are thanked for the provision of membrane modules. The project would not have been possible without the undergraduate students of the ROSI Team who contributed to the project, including Michelle Grossbach, Long Nghiem, Noriaki Endo, David Chew, Jennifer Blaikie, Long Seng To, Alistair HydePage, Deborah Lam \& Rebecca Higgins.

\section{References}

[1] Australian Bureau of Statistics. Housing and Infrastructure in Aboriginal and Torres Strait Islander Communities, Canberra, Community Housing and Infrastructure National Survey (CHINS), 1999.

[2] Australian Water Resource Council. 1985 Review of Australia's Water Resources and Water Use, Canberra, 1987

[3] Mathew K, Dallas S, Ho G, Anda M. A Solar-Powered Village Water Supply System From Brackish Water, World Renewable Energy Congress VI, 2000, p. 2061-2064.

[4] Lee T, Oppenheim D, Williamson T. Australian Solar Data Radiation Handbook (ASDRH), Energy Resource Development Council, Australia. Copyright now held by Australian and New Zealand Solar Energy Society (ANZSES), 1995.

[5] Keefer BG, Hembree RD, Schrack FC. Optimized matching of solar photovoltaic power with reverse osmosis desalination, Desalination 1985; 54: 89-103.

[6] Harrison DG, Ho GE, Mathew K. Desalination using Renewable Energy in Australia, World Renewable Energy Congress, 1996, p. 509-513.

[7] Herold D, Horstmann V, Neskakis A, Plettner-Marliani J, Piernavieja G, Calero R. Small Scale Photovoltaic Desalination for Rural Water Supply - Demonstration Plant in Gran Canaria, Renewable Energy 1998; 14(1-4): 293-298.

[8] Herold D, Neskakis A. A small scale PV-driven reverse osmosis desalination plant on the island of Gran Canaria, Desalination 2001; 137: 285-292.

[9] Joyce A, Loureiro D, Rodrigues C, Castro S. Small Reverse Osmosis Units using PV Systems for Water Purification in Rural Places, Desalination 2001; 137: 39-44.

[10] Guidelines for Drinking Water Quality. Vol. 1: Recommendations, World Health Organisation, Geneva, Switzerland, 1993.

[11] Effendi Y. Three years of experiences for PVRO-desalination, Proceedings of the $20^{\text {th }}$ IEEE Photovoltaic Specialists Conference, 1988, p. 1194-1199.
FIGURE CAPTIONS

Figure 1 The excellent solar radiation resource possess by Australia (reprinted with permission [4]). The ' $x$ ' indicates the field testing site, White Cliffs (New South Wales).

Figure 2 Overview diagram of membrane processes in water treatment.

Figure 3 Schematic diagram of the PV-powered UF/NF hybrid-membrane desalination system.

Figure 4 The reverse osmosis solar installation (ROSI) at White Cliffs.

Figure 5 The permeate flow (i) and specific energy consumption ( the system for $2000 \mathrm{mg} / \mathrm{L} \mathrm{NaCl}$ in rainwater at two different operating pressures.

Figure 6 A comparison of the system performance ( $\square$ retention; $\boxminus$ power; $\otimes$ permeate; $\square$ specific energy consumption) with dam $(150 \mathrm{mg} / \mathrm{L}$ salinity) and bore $(3500 \mathrm{mg} / \mathrm{L}$ salinity) water at an operating pressure of 5 bar.

Figure 7 The optimum operating pressure for economical water production can be found in the range $6-7$ bar when bore water is used as a feedwater ( $\boldsymbol{\square}_{\text {permeate flow; }} \boldsymbol{\Delta}$ power consumption; $\square$ specific energy consumption).

Figure 8 There is a direct relationship between the power consumption $(\mathbf{\Delta})$ of the system and the operating pressure $(O)$ of the system. Increased operating pressures require higher currents ), as measured at the output of the MPPT. This experiment was performed using dam water.

Figure 9 With decreasing solar irradiance $(\star)$ due to increasing cloud cover a slight reduction current $($ is observed, however no clear trend can be seen for the permeate flow 
Richards, B.S. ; Schäfer, A.I. (2003) Photovoltaic-powered Desalination System for remote Australian Communities, Renewable Energy 28, $2013-2022$. doi:10.1016/S0960-1481(03)00081-8

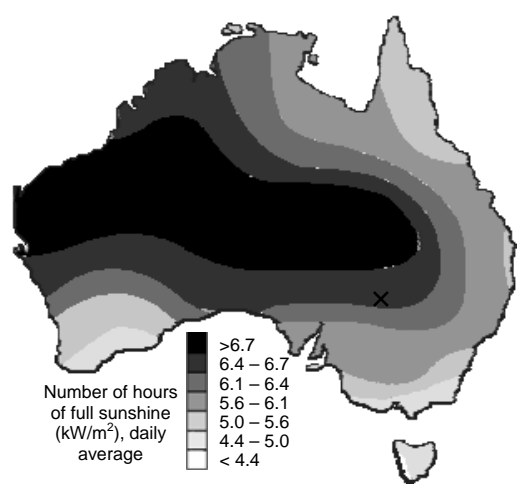

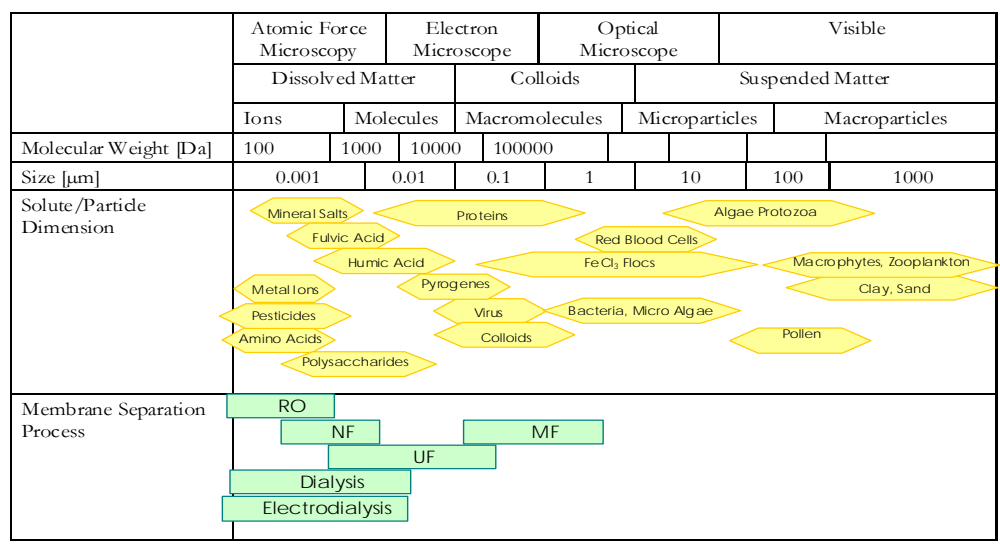


Richards, B.S. ; Schäfer, A.I. (2003) Photovoltaic-powered Desalination System for remote Australian Communities, Renewable Energy 28, $2013-2022$. doi:10.1016/S0960-1481(03)00081-8
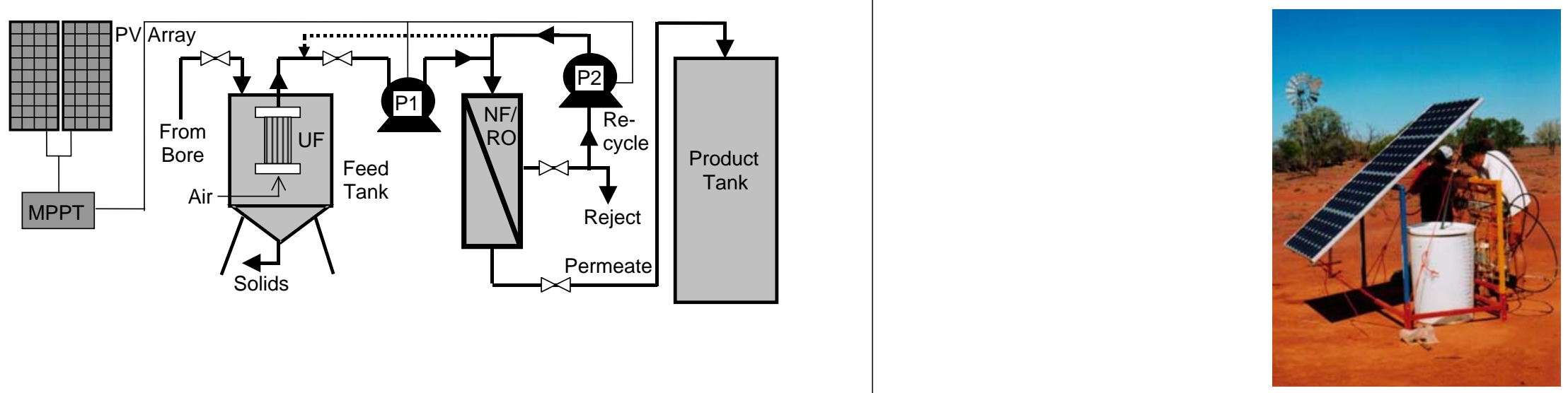
Richards, B.S. ; Schäfer, A.I. (2003) Photovoltaic-powered Desalination System for remote Australian Communities, Renewable Energy 28, $2013-2022$. doi:10.1016/S0960-1481(03)00081-8
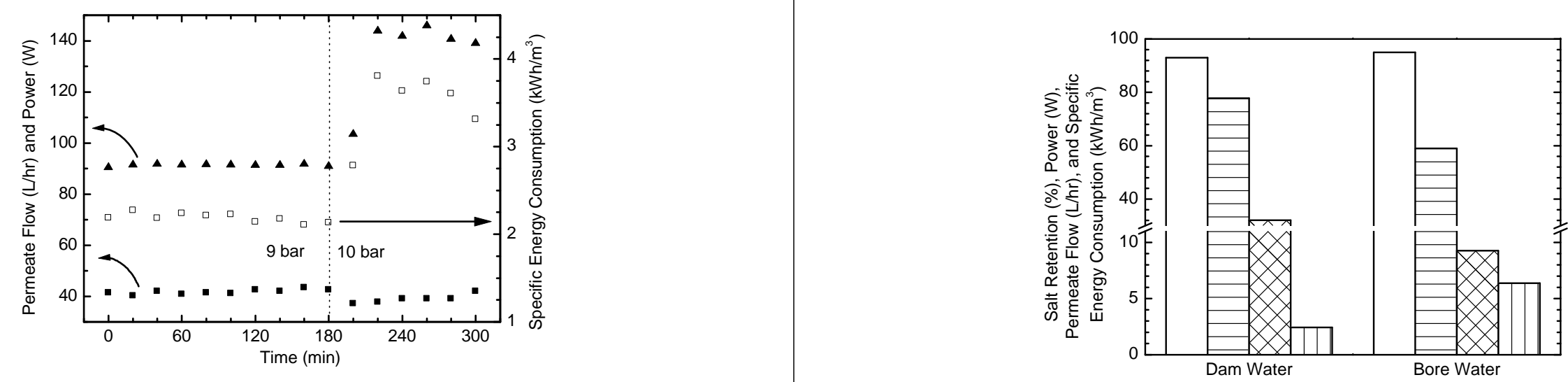
Richards, B.S. ; Schäfer, A.I. (2003) Photovoltaic-powered Desalination System for remote Australian Communities, Renewable Energy 28, 2013-2022. doi:10.1016/S0960-1481(03)00081-8
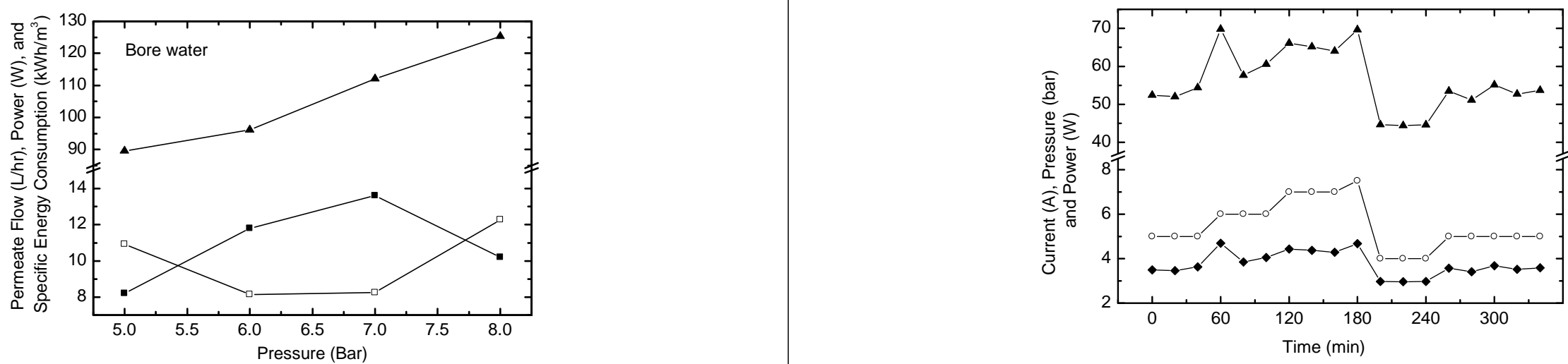
Richards, B.S. ; Schäfer, A.I. (2003) Photovoltaic-powered Desalination System for remote Australian Communities, Renewable Energy 28, $2013-2022$. doi:10.1016/S0960-1481(03)00081-8

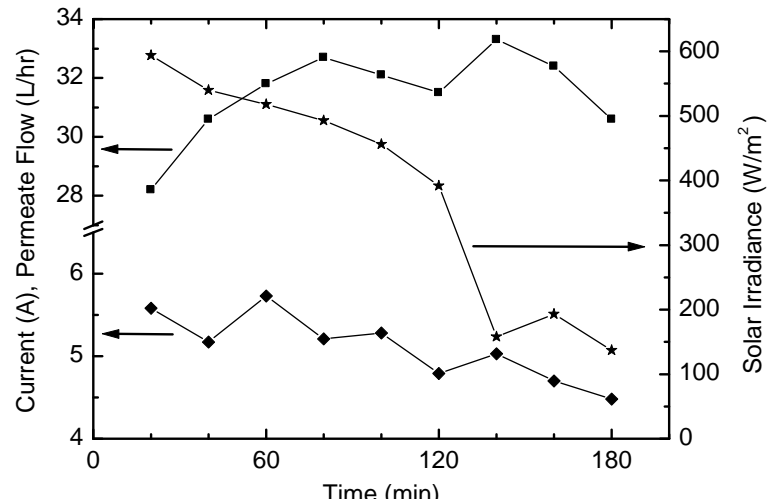

